\title{
Thinking as the others do: persistence and conformity of sexual double standard among young Italians
}

\author{
Matteo Migheli ${ }^{*}$ (D) and Chiara Pronzato ${ }^{1,2,3}$
}

\author{
*Correspondence: matteo.migheli@ \\ unito.it \\ ${ }^{1}$ Department of Economics and \\ Statistics "Cognetti de Martiis", \\ University of Torino, Lungo Dora \\ Siena, 100, I-10153 Torino (TO), Italy \\ Full list of author information is \\ available at the end of the article
}

\begin{abstract}
The double standard represents a standard of good behaviour that, unfairly, some people are expected to follow or achieve, but others are not. Once neglected by social scientists, the double standard in sexual attitudes has become more and more studied. In this paper, we inquire about the existence of the double standard in opinions regarding peers' sexual behaviours and study its determinants. What makes young people judge the sexual behaviour of women in a more conservative way than that of men? The paper uses data collected from Italian university students, who are asked to express their (dis)approval of a series of sexual behaviours, considering peers of either gender participating in those behaviours. The results show that the double standard exists and has been persistent amid Italian undergraduate students over the last 20 years, and that the cultural context matters more than the family in shaping students' beliefs.
\end{abstract}

Keywords: Sexual double standard, Peer's opinions, Parent's opinions, Italian students

\section{Introduction}

The double standard represents a standard of good behaviour that, unfairly, some people are expected to follow or achieve, but others are not. Once neglected by social scientists (Reiss, 1956), the double standard (DS) regarding sexual attitudes and behaviours, and the opinions and judgements expressed about them, has become more and more studied. Following Bordini and Sperb (2013), we may define the sexual double standard as the existence of different attitudes, viewpoints and judgements between men and women about sexual habits, behaviours and tendencies. Indeed, the literature shows that women tend to stick to traditional sexual paradigms from young ages (Bordini and Sperb, 2013 and Kukulj \& Keresteš, 2019), for example, refusing experimentation with sexual intercourse much more than men do (Lai \& Hynie, 2011). As such, the sexual DS represents a limitation to women's freedom and therefore is something that societies should carefully consider both as an indicator of distance from gender equality (Allison \& Risman, 2013) and as a way to promote the latter by reducing the former (Bobbitt-Zeher, 2011). Moreover, sexual prejudices have other negative

(c) The Author(s). 2020 Open Access This article is licensed under a Creative Commons Attribution 4.0 International License, which permits use, sharing, adaptation, distribution and reproduction in any medium or format, as long as you give appropriate credit to the original author(s) and the source, provide a link to the Creative Commons licence, and indicate if changes were made. The images or other third party material in this article are included in the article's Creative Commons licence, unless indicated otherwise in a credit line to the material. If material is not included in the article's Creative Commons licence and your intended use is not permitted by statutory regulation or exceeds the permitted use, you will need to obtain permission directly from the copyright holder. To view a copy of this licence, visit http://creativecommons.org/licenses/by/4.0/. 
effects on both social and economic terms. They are a determinant of aggressiveness against sexual minorities (Parrott \& Zeichner, 2005; Parrott et al., 2011), lead to occupational segregation (Plug et al., 2014) and ultimately decrease economic growth, as they engender an inefficient allocation of resources through discrimination (Berggren \& Elinder, 2012).

Empirical evidence shows that the sexual DS is present already in adolescence (Kreager et al., 2016), suggesting that effective policies to reduce it should target people from a young age. There are thus several reasons to study the DS, and in particular its determinants and the possible actions which may be taken to reduce it. Jackson and Cram (2003) show that the DS may be disrupted using, for instance, focus groups with young women (aged 16-18), where the language of the sexual DS is challenged and sexual desires are freely presented and discussed by the participants.

In this paper, we inquire the existence of DS in opinions about peers' sexual behaviours and study its determinants. The paper uses data collected from Italian university students, who are asked to express their (dis)approval of a series of sexual behaviours, considering peers of either gender holding those behaviours. The survey reports such information for both 2000 and 2017, allowing the observation of the evolution of sexual opinions and of the DS over time. Concerning the determinants of this phenomenon, the paper investigates how family and contextual characteristics may influence students' answers. The results show that the DS exists and has been persistent among Italian undergraduate students over the period considered and that the cultural context matters more than the familial one in shaping students' beliefs.

As Dalla Zuanna et al. (2019), this paper explores the changes in sexual behaviours of girls and boys and the related opinions, using the same data. Their focus is on the convergence between males and females' opinions over time, which is due to the feminisation of male sexual behaviour within the couple (escapades become less acceptable also for boys) and to the masculinisation of female sexual behaviour outside the couple (having more partners becomes more acceptable also for girls). Instead, the present study contributes to the literature by studying the determinants of the individual asymmetry in judging girls and boys and, in particular, the influence exerted by the reference cultural context.

\section{Related literature}

Scholars have paid much attention to the sexual opinions and attitudes of undergraduate students over the last decades. In particular, many studies focus on the existence of a DS in both behaviours and opinions. The extant literature shows that behaviours and opinions have evolved together with the existence of the DS, which has never disappeared. Ferrell et al. (1977) consider sexual attitudes and behaviours in a sample of college students in the US between 1967 and 1974; their findings show the presence of strong DS about premarital sex in all the years considered. Scott (1998), using a similar population (i.e. college students) confirms these results for both the USA and the UK, providing evidence for the existence of the DS at young ages and in highly educated people. A recent review of the literature on the DS produced in the first decade of this century (Bordini \& Sperb, 2013) highlights that several sexual behaviours are evaluated differently for men and women, while premarital sex and sexual intercourse outside 
committed relationships are more accepted for both genders now than in the past. Behaviours, norms and attitudes towards them are part of the wider and more general domain of culture ${ }^{1}$, which includes traits that may shape how people behave, think and judge others' choices. Culture is also a major factor that supports the existence of the sexual DS: in most countries, the role of women is subordinated to that of men and such a subordination included sexual initiative, with more active roles attributed to men and women assigned to more passive roles. In addition, Sakaluk and Milhausen (2012) show not only that the DS exists but also that it is stronger in the male than in the female population. More recently, Emmerink et al. (2016) find that men endorse sexual DS much more than women, probably as a consequence of the traditional sexual roles assigned to the two genders. Endendijk et al. (2020) review 99 studies through a meta-analysis and confirm that, where differences between gender roles are bigger, the DS is stronger because men have more power than women. That part of culture, which refers to gender roles, will be inquired in the analysis, as one of the aspects of interest.

The DS in sexual attitudes, behaviours and opinions is indeed pervasive, starting from the very beginning of the sexual act, i.e. the approach to the other person, as Reid et al. (2011) show in their study of hooking up among US college students. Premarital sexual intercourse was the first topic to be studied (Reiss, 1956) where the DS emerges strongly; several other works have highlighted that it is more accepted for males than for females, in accordance with the dominant cultural stereotypes (Wilson \& Medora, 1990; Ramos et al., 2005; England \& Bearak, 2014). Another related attitude involves early sexual intercourse, which is socially stigmatised in young women, but not in young men (McCarthy \& Bodnar, 2005; Kreager et al., 2016). However, many other fields of sexuality are affected by the presence of a DS, the number of sexual partners being another relevant example (Ramos et al., 2005; Bordini \& Sperb, 2013; Sprecher et al., 2013). Very recently, Marks et al. (2019) asked a sample of about 5000 US young people, aged 18-35, to evaluate the sexual behaviour of one of their friends whose sexual life they knew. The results show the emergence of a strong DS, in particular with respect to the number of sexual partners, with women evaluated worse than men as the number of partners increases. Also, the provision of condoms by women is generally seen scarcely convenient, as people in general (Smith et al., 2008) and even women in particular (Hynie \& Lydon, 1995) believe that it is more a male than a female matter. ${ }^{2}$ Jozkowski et al. (2017) show that endorsing a sexual DS also affects sexual consent communication between college students, engendering problems of misunderstanding and influencing the perception of sexual violence.

Given the focus of this paper, a digression on the so-called reverse DS is needed, with particular reference to same-sex sexual behaviours, as this is the case, where the phenomenon is most often observed. A reverse DS (i.e. more permissive attitudes towards women than towards men) is sometimes found, and generally emerges when considering same-sex sexual behaviours: here, sexual relationships between men are generally stigmatised more than between women (Siegel \& Meunier, 2019). Lesbian

\footnotetext{
${ }^{1}$ Roland (2015, p. 2) defines culture as "the set of values and beliefs people in a given community have about how the world (both nature and society) works as well as the norms of behavior derived from that set of values."

${ }^{2}$ However, some studies (Gentry, 1998; Crawford \& Popp, 2003; Marks \& Fraley, 2005) challenge the existence of such a ubiquitous DS, showing its absence with respect to some aspects of sexual life such as multiple relationships.
} 
sexual relations generally receive more positive evaluations, possibly because they are considered more erotic than sexual relations between men (Louderback and Whitley Jr., 1997). Herek (2000) found that heterosexual women hold similar attitudes toward both gay men and lesbians, whilst heterosexual men tend to accept lesbians more than gay men. Of course, such a reversion in the DS may depend on the norms that are typical of heterosexuality; as mentioned before, the DS exists because men and women have different views and attitudes towards sexual matters. In particular, the traditionally preeminent role of men and the subordinate role of women may affect how the two genders perceive and evaluate same-sex sexual behaviours. When the last is viewed as something that hinders masculinity (Javaid, 2018), the emergence of a reversed DS, when same-sex sexuality is concerned, may simply be the specular image of the DS existing in heterosexual attitudes and behaviours.

One may wonder why the sexual DS is so persistent over time. A first answer is that it is rooted in the cultural values of most modern societies, where the role of women is still seen as a subaltern to that of men. MacCorquodale (1989) highlights that the gender roles learnt at young ages are relevant in shaping gendered perceptions of sexual attitudes. Indeed, women with more egalitarian gender role attitudes and more 'masculine' personality traits are more prone to have multiple partners and exhibit more 'masculine' sexual behaviours and attitudes (Lucke, 1998). The culture of virginity, which has seen it as a positive trait for young women over centuries, is responsible for the fact that young women evaluate female virginity much more positively than men do with male virginity (Sprecher \& Regan, 1996). Always considering culture, Crawford and Popp (2003) highlight that the sexual DS is a local construction, as it depends on cultural stereotypes that vary with place. This means also that while the DS is present almost everywhere, there may be differences in judgements from a place to another, due to differences in the prevalent local cultures. Such a variation may weaken the effectiveness of large-scale policies aimed at fighting the sexual DS. Nevertheless, as the literature surveyed in what follows shows, most of the existing studies identify many traits and trends that are common to different countries (e.g. New Zealand, Turkey, UK and USA) and, therefore, cultures. Such regularities support (at least partially) the external validity of studies conducted within a specific cultural context. Yost and Zurbriggen (2006) show that unrestricted sociosexual orientation (i.e. willingness to engage in sexual relations without romantic involvement) correlates positively with premarital sex and the number of sexual partners; they also highlight the importance of the local sociocultural context for these aspects. However, for men, such an orientation correlates positively also with more conservative attitudes towards women, thus reinforcing the sexual DS. Eşsizoğlu et al. (2011) study a sample of Turkish undergraduate students, finding that traditional gender roles affect the attitude towards premarital sex: more conservative individuals-i.e. those who stick to more traditional gender roles-stigmatise premarital and early sex more than those with a more progressive vision do. Analysing the answers of US undergraduate students, Zaikman and Marks (2014) find that US individuals with more sexist attitudes also exhibit stronger DS in their evaluations of peers with multiple sexual partners.

Fasula et al. (2014) highlight the role of racial and gender inequality in explaining the existence of the sexual DS in the USA; in particular, they claim that the DS is a consequence of such inequalities. Similar conclusions are reached by Lefkowitz et al. (2014): 
US undergraduate students who exhibit conventional stereotyped beliefs about gender roles endorse a stronger DS regarding the use of condoms by women and for multipartner relations than students with a more egalitarian vision of gender roles. In the same vein, Zaikman et al. (2016) interview 483 US adults, proposing examples of gender role violations regarding sexual behaviours; their results show the emergence of a stronger DS when traditional roles are violated than when they are observed. All these studies relate the existence and the strength of a sexual DS surrounding the individual image of gender roles; thus, in a sense, the same individual is observed from two different perspectives. While individual preferences and attitudes may well depend on those diffused in the environment where the person was (and is) socialised, the individual dimension does not shed any light on environmental influence on one's preferences and attitudes.

The socio-cultural environment may shape individual preferences and attitudes-including the divide represented by the sexual DS-through the role of reputation. Indeed, departures from the dominant culture and the expectations of most people (especially parents and peers) are likely to expose those to social stigma who are not compliant with social norms. According to the literature, parents and peers are preeminently responsible for the development of opinions and judgements regarding sexual attitudes and behaviours. Young et al. (2016) highlight that Hispanic New Mexican adolescents who experience early sexual intercourse pay a social price in terms of harsher evaluations expressed by their peers; such negative opinions are stronger among women than among men, but do not differ according to the gender of the person evaluated. In particular, women with very active sexual attitudes (for example, looking for casual sex) may incur social stigma (Rudman et al., 2012). Farvis et al. (2017) show that young New Zealand women refrain from casual sex more than they would like because of reputational reasons. Reputation is mainly a matter of relationships between peers, especially in youth and adolescence. Peers contribute to shaping one's attitudes, preferences and behaviours, as the extensive literature on peer effects shows (see, for example, Tomé et al., 2012). Therefore, a good reputation is achieved when one's behaviours and choices conform to the social norms adopted by the reference group. Thus, when a sexual DS is diffused between peers, individuals adopt it, leading to situations very similar to those shown by Farvis et al. (2017). Scales (1977) provided evidence of this in the use of contraceptive techniques. Kreager and Staff (2009) show that in the USA, 'greater numbers of sexual partners are positively correlated with boys' peer acceptance, but negatively correlated with girls' peer acceptance' (2009, p. 143). Such contexts create the bases for opinions to translate into behaviours, transforming attitudinal DS into factual DS. In line with cultural stereotypes, England and Bearak (2014) show that male college students in the US are more judgmental toward women than toward men who have casual sex. Kreager et al. (2016) examine a sample of US adolescents, finding that females aged 11-16 who had or were having sexual partners were less accepted by peers than females who did not experience sexual intercourses at those ages; the opposite results are found for males. In addition, the authors' results show that peers reinforce the DS of friends and acquaintances during adolescence. However, the same study finds also a reversed DS when 'making out' is the behaviour considered: for females, this engenders increasing acceptance, while the opposite holds for males. However, it is likely that the interviewees compared 'making 
out' with sexual intercourse, judging the former relatively more suitable for females than for males. The extant literature also shows that men and women have always tended to evaluate the same behaviour differently depending on whether it is enacted by a woman or a man (Robinson \& Jedlicka, 1982). More recently, Allison and Risman (2013) have shown that in the USA, men are more prone to use it in their judgements of sexual behaviour, whilst women tend to adopt egalitarian, though conservative, positions more often than men.

Parents are also important in shaping adolescents' and young adults' attitudes and preferences, as they are the first educators of their children. The literature has examined this element, paying particular attention to two aspects: communication between parents and children on sexual issues and children's desire to adhere to their parents' expectations. In general, talking with parents about sex and related issues (such as contraception) is associated with more sexual permissiveness; however, Californian adolescents who talk about sex with their parents also show stronger gendered stereotypes about sexual issues (Morgan et al., 2010). US women who did not talk about sexuality with their parents in their adolescence are more likely to stick to traditional paradigms, reinforcing the existence of the sexual double standard (Montemurro et al., 2015). On the second point (willingness to meet parents' expectations), Shoveller et al. (2004) highlight that Canadian adolescents aim at conforming to parents' expectations; along the same lines, from the literature review of Fugère et al. (2008), the concern of children about parental disapproval of their sexual behaviour emerges as a factor shaping the sexual attitudes of young adults. Aksun and Ataca (2007) provide evidence that when Turkish children perceive restrictive sexual values and attitudes in their parents, they tend to postpone their first sexual intercourse and enjoy it less than do young adults who perceive their parents to be more liberal.

Religiosity represents another relevant individual trait that predicts the endorsement of the sexual DS. Scott (1998) highlights the importance of religious beliefs in shaping this evolution, with religious people more reluctant to adopt permissive sexual behaviours. Using a sample of undergraduate students recruited in the Eastern USA, Lefkowitz et al. (2004) show that religious people stick to more conservative sexual behaviours than non-religious. Esssizoğlu et al. (2011) study the DS regarding virginity and premarital status in Turkish universities and find that both religious males and females are more likely than non-religious to remain virgins until marriage, although the effect is stronger for women than for men. In line with the literature on value transmission from parents to children, Landor et al. (2011) find evidence that in the USA, young Afro-American adults with religious parents are less likely to start having sex at early ages and to have multiple sexual partners. This result may also be interpreted in the light of studies which suggest that young people generally try to meet their parents' expectations in terms of compliance with moral norms. Emmerink et al. (2016) show that a strong and positive relationship between religiosity and traditional gender attitudes exists and is responsible for the presence of sexual DS in a sample of young Dutch people. Religious attitudes are generally found to be responsible for both traditional visions of gender roles (Morgan, 1987; Glick et al., 2002), and sexual DS (Ali \& Gordon, 2018).

The relationships found in these articles linking the existence of sexual DS to peers' and parents' attitudes towards sexuality, however, may indicate that both children and 
parents living in less traditional families talk more about sexuality than people living in more traditional families. Therefore, there may be a self-reinforcing mechanism working against the sexual double standard in such families. The analysis proposed in the present paper will try to minimise this issue of endogeneity, as explained in the section devoted to illustrating the methodology.

This paper contributes to the literature by analysing the determinants of the DS with individual data: what makes young people judge women's sexual behaviour in a more conservative way than that of men? The present inquiry refers to Italy, which is a country characterised by a variety of social and cultural contexts, with significant-and thus exploitable-variability of the level of liberalism with respect to sexual matters between regions. While such variability is not exhaustive of all possible cultures, nevertheless, it adds support to the generalisability of the results.

\section{Data and methods}

This paper uses information collected through the SELFY survey (Dalla Zuanna et al., 2019), carried out in the years 2000 and 2017, over a sample of Italian undergraduate students in economics and statistics. The questionnaire includes several questions about the emotional and sexual life of students, together with information about their family, their childhood and adolescence. The questionnaire was filled in by students during a regular lecture. After completion, the questionnaire was inserted in an envelope, in order to ensure privacy and anonymity. A total of 12,064 respondents (4762 in 2000 and 7842 in 2017) filled in the questionnaire. On the one hand, we have good sample sizes; on the other hand, University students in Economics and Statistics do not represent the whole population of young Italians. With respect to the representativeness and other characteristics of the survey, the reader can refer to a detailed description of both the questionnaire and the data is available in Dalla Zuanna et al. (2019).

The questions from the SELFY database used in this paper focus on the respondents' opinions of certain sexual behaviours. In particular, the interviewees are asked whether they approve or disapprove a certain behaviour, once enacted by a female, once by a male. The behaviours evaluated are the following: (1) having very early sexual relations, (2) having escapades while in a relationship with a person, (3) having sexual relations with multiple partners, without having a fixed partner, (4) remaining a virgin until a relatively high age, (5) remaining a virgin until marriage and (6) having sex with people of the same sex. Each respondent is asked to express his or her approval on a four-digit scale. We focus our analysis on more extreme (conservative) opinions: ${ }^{3}$ whether the interviewed person strongly disapproves of behaviours 1, 2, 3 and 6 and whether he or she strongly approves of behaviours 4 and 5 . We then define the double standard (DS) as the presence of more conservative judgements of females about the analysed behaviours and the reverse double standard (RDS) as the presence of more conservative judgements of males about the same behaviours. Table 1 reports the main figures. For

\footnotetext{
${ }^{3}$ An alternative definition of the DS could have been the difference between the degree of approval expressed for males and that for females. However, such a variable would present at least two weaknesses. The first is the translation of verbal responses into numbers: on the one hand, the use of a linear transformation would entail assuming equidistance between the preferences, without any support for such an assumption. On the other hand, any functional form used would be arbitrary, and the results may depend on the transformation applied to the responses. In addition, a numerical transformation would implicitly assume the same distance between degrees of agreement for all the respondents.
} 
Table 1 (Dis)approval of certain sexual behaviours (by both males and females), double standard (DS) and reverse double standard (RDS)

\begin{tabular}{|c|c|c|c|c|c|c|c|c|}
\hline & \multicolumn{4}{|l|}{2000} & \multicolumn{4}{|l|}{2017} \\
\hline & Females & Males & DS & RDS & Females & Males & DS & $\overline{R D S}$ \\
\hline & $\%$ & $\%$ & $\%$ & $\%$ & $\%$ & $\%$ & $\%$ & $\%$ \\
\hline I do not approve of very early sexual relations & 49.8 & 33.5 & 17.2 & 1.2 & 42.6 & 25.6 & 18.2 & 1.4 \\
\hline I do not approve of having escapades & 76.0 & 69.3 & 9.2 & 2.9 & 77.2 & 70.6 & 8.4 & 2.1 \\
\hline $\begin{array}{l}\text { I do not approve of having sexual relations with } \\
\text { multiple partners }\end{array}$ & 44.7 & 34.4 & 11.1 & 1.1 & 35.1 & 25.9 & 10.3 & 1.1 \\
\hline $\begin{array}{l}\text { I do approve of remaining a virgin until a relatively } \\
\text { high age }\end{array}$ & 25.9 & 20.9 & 8.3 & 3.2 & 20.3 & 16.3 & 5.0 & 1.1 \\
\hline I do approve of remaining a virgin until marriage & 27.1 & 22.0 & 7.9 & 2.1 & 15.8 & 13.1 & 3.3 & 0.6 \\
\hline $\begin{array}{l}\text { I do not approve of having sex with people of the } \\
\text { same sex }\end{array}$ & 54.0 & 60.3 & 2.2 & 8.0 & 22.4 & 32.6 & 2.2 & 12.1 \\
\hline
\end{tabular}

Notes: the gender reported as heads of columns is that of people whose behaviour is assessed. The number of missing responses is different for the different opinions. The number of observations goes from 4333 (remaining a virgin until a high age) to 4394 (not approving of escapades) for female behaviours in 2000, from 4368 (remaining a virgin until a high age) to 4,433 (not approving of early sexual relationships) for male behaviours in 2000, from 7090 (remaining a virgin until marriage) to 7169 (not approving of early sexual relationships) for female behaviours in 2017, from 7125 (remaining a virgin until marriage) to 7208 (not approving of early sexual relationships) for male behaviours in 2017

example, we observe that $49.8 \%$ of respondents to the 2000 survey do not approve of very early sexual behaviours in women, while $33.5 \%$ do not approve the same behaviour for men. $17.2 \%$ state that women should not engage in very early sexual behaviours while men may do so. On the other hand, $1.2 \%$ state that men should not have very early sexual behaviours while women may do so. Comparing responses from the 2017 survey to responses from the 2000 survey gives an immediate idea of the extent to which young people have become more sexually progressive. The largest difference concerns same-sex sexual behaviours: $54-60 \%$ negatively judged having sex with partners of the same sex in 2000, only $22-33 \%$ in 2017. Opinions remain more constant over time when considering escapades: an invariant percentage of around 70 used $75 \%$ of students do not approve of escapades while being in a relationship with a person. Among students who judge differently women and men, we observe, as expected, a larger proportion of students evaluating women in a more conservative way for all behaviours, with the exception of having same-sex sexual relations. The RDS, in this case, has even increased between 2000 and 2017.

The goal of the paper is to understand how the cultural framework (paying particular attention to gender roles in society) where students were socialised during their adolescence impacts their opinions and judgements regarding sexual behaviours. The analysis takes into consideration the attitudes towards gender equality that prevail in the region (NUTS-2 level) where the interviewees were enrolled in upper-secondary school. In the Italian school system, people enrol in upper-secondary school when they are 14, and the legal duration is five years, i.e. the students normally leave this level of education when they are 19. Information about gender equality sentiments in the twenty Italian regions comes from the World Values Survey (2008). We use the responses to seven questions. The interviewed person was asked her or his level of agreement (disagree strongly, disagree, agree and agree strongly) with the following statements: (1) a preschool child suffers with a working mother; (2) what women really want is a home and children; (3) being a housewife is as fulfilling as having a paid job; (4) a job is the best way for women to be independent; (5) husbands and wives should both contribute to 
the household income; (6) fathers are as well suited to look after children as mothers; (7) men should take the same responsibility for home and children. Given the large number of items, a principal component analysis was carried out, and components with eigenvalues greater than one were extracted. Table 2 presents the correlations between each component and the answers to the seven original questions. As the correlations show, the components capture different attitudes towards gender equality: the first is highly positively correlated with items expressing a traditional division of family and work duties between women and men (we will refer to it as 'Traditional division of responsibilities'), while the second is highly correlated with items expressing the importance of women outside the family (we will refer to it as 'Working women'). The third is correlated with the item expressing differences between mothers and fathers in their abilities to care for children (we will refer to it as 'different caring attitudes').

We are interested in testing the relationship between the view of gender roles in society and how students evaluate selected sexual behaviours when performed by females or males. We, therefore, estimate the following equation:

$$
Y_{i, b}^{*}=\alpha_{b}+G_{r}^{\prime} \beta_{b}+X_{i}^{\prime} \gamma_{b}+\lambda_{b} T+e_{i, b}
$$

where $Y_{i, b}{ }^{*}$ is a latent variable that captures the probability of a student $i$ to be more conservative when judging a certain sexual behaviour $b$ held by one gender compared to the other gender. If $Y_{i, b}{ }^{*}>0$, we observe $Y_{i, b}=1$, which indicates the presence of a DS in all outcomes other than the one concerning same-sex sexuality. The vector $G$ indicates the first two gender-roles factors at a regional level, ${ }^{4}$ while $\mathrm{X}$ indicates the individual and family control variables. $T$ is a dummy variable indicating the more recent survey carried out in 2017, and $e_{i, b}$ is the individual error that follows a logistic cumulative distribution. Errors are clustered at the regional level. When the estimated coefficients $\beta$ are negative, that implies that differences between judgements are reduced in region when the factor $\mathrm{G}$ is high.

Each individual in the dataset is assigned the value of the components relative to the region where he or she lived while attending secondary school. We include, as controls, two demographic characteristics of the student (age and gender) found to be important determinants of the DS and two characteristics of the family (level of education and religiosity) that can be related to the view of gender roles in society and have a direct impact on students' judgement. ${ }^{5}$ Students' age is concentrated between 20 and 21 years (around $70 \%$ ) but may reach 26 years (25\% are older than 21 ). As for religiosity, we consider mothers' services attendance when the student was 13 years old. The dummy variable takes value 1 when she was attending services at least $2 / 3$ times a month. The relative descriptive statistics are reported in Table 3.

\section{Results}

Table 4 comprises the results. At first sight, we see that the regional dimension matters more than the personal/family ones. We observe that living in a region with a strong preference for a traditional division of responsibilities increases the DS: women are

\footnotetext{
${ }^{4}$ We did not include the third factor (different care attitudes) since it was never significant.

${ }^{5} \mathrm{We}$ estimated models with larger numbers of controls, which never happened to be significant: being the firstborn, having siblings, parental separation, parents' work conditions, and size of the place of residence during adolescence. Results available upon request.
} 
Table 2 Correlation between factors and responses to the questions in the World Value Survey (2008)

\begin{tabular}{llll}
\hline & $\begin{array}{l}\text { Traditional division } \\
\text { of responsibilities }\end{array}$ & $\begin{array}{l}\text { Working } \\
\text { women }\end{array}$ & $\begin{array}{l}\text { Different caring } \\
\text { attitudes }\end{array}$ \\
\hline A pre-school child suffers with a working mother & -0.299 & 0.659 & 0.347 \\
What women really want is a home and children & -0.377 & 0.694 & -0.161 \\
Being a housewife is as fulfilling as having a paid job & -0.479 & 0.490 & 0.445 \\
A job is the best way for women to be independent & 0.692 & 0.204 & -0.412 \\
Husband and wife should both contribute to the HH income & 0.702 & 0.260 & -0.269 \\
Fathers are as well suited to look after children as mothers & 0.568 & 0.282 & 0.537 \\
Men should take the same responsibility for home and children & 0.605 & 0.347 & 0.360 \\
Observations & 1.100 & &
\end{tabular}

Notes: high values of the statements indicate strong disagreement

judged more severely in their sexual sphere. On the other hand, regions characterised by more progressive attitudes towards women in the labour market show lower values of DS. In the only case of RDS (sex with a same-sex partner), we also estimate a negative impact from the more progressive factor. This does not seem a coincidence, given that the "working women" factor is the one that brings women closer to a traditionally more masculine context (work outside the home) and men to a traditionally more feminine context (care work).

With respect to the other variables included in the model, we generally observe that women, as expected, are more likely to judge women and men in the same way, including in the case of same-sex sexuality. The strongest effect is found in case of same-sex relations, where girls are three times more likely to judge boys and girls in the same way. The only exception appears for 'remaining a virgin until a relatively high age', where females tend to say that this is more important for themselves than for men.

When significant, the estimated effect of age shows that older students are more likely to judge female and male sexual behaviours in the same way.

Parental background seems to matter only for remaining a virgin until marriage, where having a religious mother makes this behaviour more desirable for females; having higher education reduces the distance between females and males. Surprisingly, living in a religious family environment also shortens the distance between females and males concerning escapades. This could be because this behaviour is considered so unacceptable in general (see Table 1), particularly for religious people, that the difference between genders is smaller.

Over the passage of time, we observe an improvement in equality between men and women when their sexual behaviour is judged: the dummy indicating the survey carried out in 2017 is almost always negative; exceptions are present for 'very early sexual

Table 3 Control variables

\begin{tabular}{lll}
\hline & 2000 & 2017 \\
\hline Student's age & 21.0 & 21.1 \\
Student is female (\%) & 59.8 & 48.2 \\
At least one parent has tertiary education (\%) & 22.6 & 31.6 \\
Religious mother (\%) & 49.8 & 37.3 \\
Observations & 4,350 & 7,151 \\
\hline
\end{tabular}

Notes: the descriptive statistics refer to the sample of students without missing values among the control variables and with at least one complete answer among the six opinions 
Table 4 The determinants of DS/RDS

\begin{tabular}{|c|c|c|c|c|c|c|c|c|c|}
\hline \multirow[b]{3}{*}{ Student's age } & \multicolumn{2}{|l|}{ Coeff. } & St. err. & \multicolumn{3}{|l|}{ Sign. } & \multicolumn{2}{|l|}{ Coeff. } & St. err. \\
\hline & \multicolumn{2}{|c|}{$\begin{array}{l}\text { Early sexual } \\
\text { relations (DS) }\end{array}$} & \multirow[b]{2}{*}{$*$} & \multicolumn{2}{|c|}{ Escapades (DS) } & \multirow[b]{2}{*}{$* * *$} & \multicolumn{2}{|c|}{$\begin{array}{l}\text { Multiple } \\
\text { partners (DS) }\end{array}$} & \\
\hline & -0.040 & 0.021 & & -0.063 & 0.022 & & -0.075 & 0.026 & $* * *$ \\
\hline Student is female & -0.249 & 0.069 & $* * *$ & -3.229 & 0.146 & $* * *$ & -0.742 & 0.069 & $* * *$ \\
\hline Parents' tertiary education & 0.028 & 0.067 & & 0.114 & 0.090 & & -0.075 & 0.062 & \\
\hline Religious mother & 0.058 & 0.051 & & -0.108 & 0.051 & $* *$ & -0.045 & 0.070 & \\
\hline Year 2017 & 0.029 & 0.058 & & -0.441 & 0.078 & $* * *$ & -0.220 & 0.090 & ** \\
\hline $\begin{array}{l}\text { Traditional division of } \\
\text { responsibilities }\end{array}$ & 0.451 & 0.091 & $* * *$ & 0.364 & 0.203 & * & 0.789 & 0.275 & $* * *$ \\
\hline Working women & -0.194 & 0.088 & $* *$ & -0.390 & 0.194 & ** & -0.454 & 0.146 & $* * *$ \\
\hline Constant & -0.637 & 0.466 & & 0.031 & 0.493 & & -0.104 & 0.547 & \\
\hline \multirow[t]{2}{*}{ Observations } & \multicolumn{2}{|l|}{11,274} & & \multicolumn{2}{|l|}{11,306} & & \multicolumn{2}{|l|}{11,295} & \\
\hline & \multicolumn{2}{|c|}{$\begin{array}{l}\text { Virgin until high } \\
\text { age (DS) }\end{array}$} & & \multicolumn{2}{|c|}{$\begin{array}{l}\text { Virgin until } \\
\text { marriage (DS) }\end{array}$} & & \multicolumn{3}{|c|}{$\begin{array}{l}\text { Sex with same-sex } \\
\text { partner (RDS) }\end{array}$} \\
\hline Student's age & -0.005 & 0.024 & & -0.003 & 0.041 & & -0.058 & 0.027 & $* *$ \\
\hline Student is female & 0.237 & 0.077 & $* * *$ & -0.283 & 0.045 & $* * *$ & -2.903 & 0.106 & $* * *$ \\
\hline Parents' tertiary education & -0.016 & 0.126 & & -0.210 & 0.057 & $* * *$ & 0.022 & 0.059 & \\
\hline Religious mother & 0.033 & 0.054 & & 0.267 & 0.075 & $* * *$ & 0.062 & 0.073 & \\
\hline Year 2017 & -0.294 & 0.101 & $* * *$ & -0.703 & 0.113 & $* * *$ & 0.237 & 0.120 & * \\
\hline $\begin{array}{l}\text { Traditional division of } \\
\text { responsibilities }\end{array}$ & 0.534 & 0.260 & $* *$ & 1.426 & 0.462 & $* * *$ & -0.206 & 0.170 & \\
\hline Working women & -0.537 & 0.225 & $* *$ & -0.627 & 0.240 & $* * *$ & -0.465 & 0.171 & $* * *$ \\
\hline Constant & -2.737 & 0.475 & $* * *$ & -2.702 & 0.901 & $* * *$ & -0.326 & 0.581 & \\
\hline Observations & 11,194 & & & 11,188 & & & 11,196 & & \\
\hline
\end{tabular}

relations' and 'having sex with same-sex partners'. These hardly significant results could be due to the drastic reduction in the share of students who do not approve of early relations and, especially, who do not approve of same-sex sexual relations between 2000 and 2017, which have not been linear for either sex. The estimated coefficient is instead negative and particularly strong in case of escapades and multiple partners, recalling results reported by Dalla Zuanna et al. (2019): "escapades" become less bearable for boys and "multiple partners" becomes more bearable for girls, making judgements between girls and boys closer.

By interacting the two regional factors with the dummy variable reporting the year of the survey, we get a few but interesting results. In the case of "remaining a virgin until a relatively high age", we find that the reduction in the double standard over time is larger for more traditional regions. On the other hand, for "having sex with people of the same sex", for which observe a general increase of the reverse double standard between 2000 and 2017, more equality between judgments over time is due to more modern regions. ${ }^{6}$

How quantitatively important are these findings? Let us compare two identical average students (males, 21 years old, in 2017, with low parental education and without a religious mother) in two very different contexts: one region characterised by high 
conservativism, the other region characterised by very high progressivism (see values in Table 5). ${ }^{7}$ The student raised in the more traditional context is three times more likely to say that a girl (though not a boy) should remain a virgin until marriage than the student raised in the less traditional regions (the probability of DS goes from 0.10 to 0.03 ). The first student is twice as likely to be more severe with girls when judging the fact of having multiple partners (even if not in a fixed relationship) or the importance of remaining a virgin until a high age. The probability of DS is also reduced when judging early sexual relationships and escapades. There is no effect on the RDS concerning same-sex sexual relationships. ${ }^{8}$

Are these effects large with respect to the ones related to the family? Generally, yes, looking at the non-significance of the family variables in most cases. Let us simulate the only relevant outcome, 'virgin until marriage': while we observed a reduction of seven percentage points due to the context, tertiary education would reduce the share of students with DS by two percentage points, and having a religious mother would increase this proportion by $2.5 \%$.

These gendered attitudes towards sexual behaviour seem to be primarily due to the environment where students grew up. We know not only the region where students spent their adolescence, but also where they were born, where they currently study, and where they officially reside at present. Repeating the analyses with factors related to the region of birth would leave the results unchanged, while using current regions would reduce the significance of the cultural dimensions.

\section{Conclusions}

Starting with two surveys conducted among Italian undergraduate students, this paper has inquired into the existence of sexual DS in Italy in 2000 and 2017. The results are in line with extant literature that shows both the existence of sexual DS among the young. The novelty of the analysis, however, lies in the connection found between the cultural context of origin and the opinions of the interviewees towards some sexual behaviours. The results show that students from areas with more conservative backgrounds exhibit stronger DS than their peers raised in more progressive contexts. Italy offers sufficient socio-cultural differences across its regions to render analysis possible within one country. This has an additional positive aspect: a common language. Indeed, when translated into different languages, the same questions may present different nuances of meaning to respondents in different linguistic areas.

The analysis considers both the familial and regional contexts of the student, showing that the second matters more than the first in shaping the opinions of the interviewees. This phenomenon, however, suggests that the sexual DS will be very hard to eradicate for at least two reasons. First, the culture of a region changes slowly and is difficult, if not impossible, to influence from outside. Second, the evidence proposed in the paper also suggests that these cultural traits are very likely to be reproduced through younger generations' conformity to them. A possible interpretation of the results in light of the extant literature is that undergraduate students aim at conforming to opinions from

\footnotetext{
${ }^{7}$ The values chosen for the simulation and reported in Table 5 are realistic and taken from the distribution of the variables observed in the data.

${ }^{8}$ The negative effect is driven by the negative sign of the coefficient 'Traditional division of responsibilities' (Table 4), which, however, is not significant.
} 
Table 5 Simulated context effects

\begin{tabular}{lll}
\hline & $\begin{array}{l}\text { Traditional region } \\
(\%)\end{array}$ & $\begin{array}{l}\text { Modern region } \\
(\%)\end{array}$ \\
\hline A pre-school child suffers with a working mother (agree) & 90 & 50 \\
What women really want is a home and children (agree) & 80 & 50 \\
Being a housewife is as fulfilling as having a paid job (agree) & 80 & 40 \\
A job is the best way for women to be independent (disagree) & 40 & 10 \\
Husband and wife should both contribute to the HH income (disagree) & 40 & 10 \\
Fathers are as well suited to look after children as mothers (disagree) & 60 & 10 \\
Men should take the same responsibility for home and children (disagree) & 20 & 10 \\
Predicted factor: traditional division of responsibilities & 1.03 & 0.23 \\
Predicted factor: working women & 0.39 & 0.69 \\
Predicted DS (early sexual relations) & 0.26 & 0.19 \\
Predicted DS (escapades) & 0.18 & 0.13 \\
Predicted DS (multiple partners) & 0.22 & 0.12 \\
Predicted DS (virgin until high age) & 0.06 & 0.03 \\
Predicted DS (virgin until marriage) & 0.10 & 0.03 \\
Predicted RDS (sex with same-sex partner) & 0.15 & 0.16
\end{tabular}

Notes: the top panel reports the percentage of people with traditional views in the most and least traditional regions (the values are realistic and taken from the distribution of the variables observed in the data). The middle panel reports the predicted values of the factors (using the loadings of the principal component analysis, see "Data and methods" section). The bottom panel reports the probabilities of DS/RDS for a male student, in 2017, aged 21 years old, whose parents do not have a tertiary education and whose mother is not religious (predictions are computed using the parameters displayed in Table 4)

people in the original region more than those of their parents because the first is more important for social acceptance.

Endendijk et al. (2020) may provide an interesting ground on which discussing the results presented here, inasmuch as the authors show two main results that are of particular interest here. On the one hand, the widespread existence of the DS emerges from the extant literature; on the other hand, gender equality works a moderator of the phenomenon. The results from the sample of Italian undergraduate students presented here are in line with both these findings, suggesting that not only their validity is more than internal, but also that traditional cultural frameworks may amplify and increase the time persistence of the DS.

\section{Acknowledgements}

The authors acknowledge the useful suggestions and comments received by the other authors of SELFY initiative during a dedicated workshop in Firenze and the annual meeting of the Italian Population Society in Milano.

\section{Data availability}

The data used in this paper are part of SELFY project: a research projects that involves several Italian universities, which are the proprietaries of the data. These may be requested to the responsible of data for the project, Professor Alessandra Minello (alessandra.minello@unifi.it).

\section{Authors' contributions}

$\mathrm{CP}$ is responsible for data collection, data analyses and comments to such analyses. MM is responsible for the introduction and the literature review. The two authors equally wrote the conclusions of the paper. Both authors read and approved the final version of the manuscript.

\section{Funding}

No funds were received for this study.

\section{Author details}

'Department of Economics and Statistics "Cognetti de Martiis", University of Torino, Lungo Dora Siena, 100, I-10153 Torino (TO), Italy. ${ }^{2}$ CHILD-Collegio Carlo Alberto, Piazza Arbarello, 8, I-10122 Torino (TO), Italy. ${ }^{3}$ DONDENA, Boccony University, Piazza Sraffa 11, 20136 Milano (MI), Italy. 
Received: 8 November 2019 Accepted: 6 August 2020

Published online: 24 August 2020

\section{References}

Aksun, D., \& Ataca, B. (2007). Sexually related attitudes and behaviors of Turkish university students. Archives of Sexual Behavior, 36(5), 741-752.

Ali, A., \& Gordon, N. (2018). Traditional gender roles: Social and cultural influences on oppression and resistance. In J. T. Nadler, \& M. R. Lowery (Eds.), The war on women in the United States: Beliefs, tactics, and the best defenses, (pp. 31-221). Santa Barbara, CA: Praeger.

Allison, R., \& Risman, B. J. (2013). A double standard for "hooking up": How far have we come toward gender equality? Social Science Research, 42(5), 1191-1206.

Berggren, N., \& Elinder, M. (2012). Is tolerance good or bad for growth? Public Choice, 150(1-2), 283-308.

Bobbitt-Zeher, D. (2011). Gender discrimination at work: Connecting gender stereotypes, institutional policies, and gender composition of workplace. Gender \& Society, 25(6), 764-786.

Bordini, G. S., \& Sperb, T. M. (2013). Sexual double standard: A review of the literature between 2001 and 2010. Sexuality \& Culture, 17(4), 686-704.

Crawford, M., \& Popp, D. (2003). Sexual double standards: A review and methodological critique of two decades of research. The Journal of Sex Research, 40(1), 13-26.

Dalla Zuanna, G., Caltabiano, M., Minello, A., \& Vignoli, D. (2019). Catching up! The sexual opinions and behaviour of Italian students (DISIA Working Paper n. 2019/02). University of Firenze.

Emmerink, P. M. J., Vanwesenbeek, I., van der Eijnden, R. J. J. M., \& ter Bogt, T. F. M. (2016). Psychosexual correlates of sexual double standard endorsement in adolescent sexuality. The Journal of Sex Research, 53(3), 286-297.

Endendijk, J. J., van Baar, A. L., \& Deković, M. (2020). He Is a Stud, She Is a Slut! A Meta-Analysis on the Continued Existence of Sexual Double Standards. Personality and Social Psychology Review, 24(2), 163-190.

England, P., \& Bearak, J. (2014). The sexual double standard and gender differences in attitudes toward casual sex among U.S. university students. Demographic Research, 30(46), 1327-1338.

Eşsizoğlu, A., Yasan, A., Yildirim, E. A., Gurgen, F., \& Ozkan, M. (2011). Double standard for the traditional value of virginity and premarital sexuality in Turkey: A university students case. Women \& Health, 51(1), 136-150.

Farvis, P., Braun, V., \& Rowney, C. (2017). "No girl wants to be called a slut!": Women, heterosexual casual sex and the sexual double standard. Journal of Gender Studies, 26(5), 544-560.

Fasula, A. M., Carry, M., \& Miller, K. S. (2014). A multidimensional framework for the meanings of the sexual double standard and its application for the sexual health of young black women in the U.S. The Journal of Sex Research, 51(2), 170-183.

Ferrell, M. Z., Tolone, W. L., \& Walsh, R. H. (1977). Maturational and societal changes in the sexual double-standard: A panel analysis (1967-1971; 1970-1974). Journal of Marriage and Family, 39(2), 255-271.

Fugère, M. A., Escoto, C., Cousins, A. J., Riggs, M. L., \& Haerich, P. (2008). Sexual attitudes and double standards: A literature review focusing on participant gender and ethnic background. Sexuality and Culture, 12(3), 169-182.

Gentry, M. (1998). The sexual double standard. Psychology of Women Quarterly, 22(3), 505-511.

Glick, P., Lameiras, M., \& Rodriguez Castro, Y. (2002). Education and Catholic religiosity as predictors of hostile and benevolent sexism towards women and men. Sex Roles, 47(9-10), 433-441.

Herek, G. M. (2000). Sexual prejudice and gender: Do heterosexuals' attitudes towards lesbians and gay men differ? Journal of Social Issues, 56(2), 251-266.

Hynie, M., \& Lydon, J. E. (1995). Women's perception of female contraceptive behavior: Experimental evidence of the sexual double standard. Psychology of Women Quarterly, 19(4), 563-581.

Jackson, S. M., \& Cram, F. (2003). Disrupting the sexual double standard: Young women's talk about heterosexuality. British Journal of Social Psychology, 42(1), 113-127.

Javaid, A. (2018). In J. Ed (Ed.), "Hegemonic Masculinity, Heteronormativity and Male Rape" in Male Rape, Masculinities and Sexualities A. Cham: Springer.

Jozkowski, K. N., Marcantonio, T. L., \& Hunt, M. E. (2017). College students' sexual consent communication and perception of sexual double standards: A qualitative investigation. Perspective on Sexual and Reproductive Health, 49(4), $237-244$.

Kreager, D. A., \& Staff, J. (2009). The sexual double standard and adolescent peer acceptance. Social Psychology Quarterly, 72(2), 143-164.

Kreager, D. A., Staff, J., Gauthier, R., Lefkowitz, E. S., \& Feinberg, M. E. (2016). The double standard at sexual debut: Gender, sexual behavior and adolescent peer acceptance. Sex Roles, 75(7), 377-392.

Kukulj, S., \& Keresteš, G. (2019). Sexual self-schemas of Croatian university students: Gender differences and links with sexual activity. Sexuality \& Culture, 23(3), 848-861.

Lai, Y., \& Hynie, M. (2011). A tale of two standards: An examination of young adults' endorsement of gendered and ageist sexual double standards. Sex Roles, 64(5-6), 360-371.

Landor, A., Simons, L. G., Simons, R. L., Brody, G. H., \& Gibbons, F. X. (2011). The role of religiosity in the relationship between parents, peers and adolescent risky sexual behavior. Journal of Youth and Adolescence, 40(3), 296-309.

Lefkowitz, E. S., Gillen, M. M., Shearer, C. L., \& Boone, T. L. (2004). Religiosity, sexual behaviors, and sexual attitudes during emerging adulthood. The Journal of Sex Research, 41(2), 150-159.

Lefkowitz, E. S., Shearer, C. L., Gillen, M. M., \& Espinosa-Hernandez, G. (2014). How gendered attitudes relate to women's and men's sexual behaviors and beliefs. Sexuality \& Culture, 18(4), 833-846.

Louderback, L. A., \& Whitley Jr., B. E. (1997). Perceived erotic value of homosexuality and sex-role attitudes as meditators of sex differences in heterosexual college students' attitudes towards lesbians and gay men. The Journal of Sex Research, 34(2), 175-182.

Lucke, J. C. (1998). Gender roles and sexual behavior among young women. Sex Roles, 39(3-4), 273-297.

MacCorquodale, P. (1989). Gender and sexual behavior. In K. McKinney, \& S. Sprecher (Eds.), Human Sexuality: The Societal and Interpersonal Context. Norwood, NJ: Ablex.

Marks, M. J., \& Fraley, R. C. (2005). The sexual double standard: Fact or fiction? Sex Roles, 52(3/4), 175-186.

Marks, M. J., Young, T. M., \& Zaikman, Y. (2019). The sexual double standard in the real world. Social Psychology, 50(2), 67-79. 
McCarthy, B. W., \& Bodnar, L. E. (2005). The equity model of sexuality: Navigating and negotiating the similarities and differences between men and women in sexual behaviour, roles and values. Sexual and Relationship Therapy, 20(2), 225-235.

Montemurro, B., Bartasavich, J., \& Wintermute, L. (2015). Let's (not) talk about sex: The gender of sexual discourse. Sexuality and Culture, 19(1), 139-156.

Morgan, E. M., Thorne, A., \& Zurbriggen, E. L. (2010). A longitudinal study of conversations with parents about sex and dating during college. Development Psychology, 46(1), 139-150.

Morgan, M. Y. (1987). The impact of religion on gender-role attitudes. Psychology of Women Quarterly, 11(3), 301-310.

Parrott, D. J., Peterson, J. L., \& Bakeman, R. (2011). Determinants of aggression towards sexual minorities in a community sample. Psychology of Violence, 1(1), 41-52.

Parrott, D. J., \& Zeichner, A. (2005). Effects of sexual prejudice and anger on physical aggression towards gay and heterosexual men. Psychology of Men and Masculinity, 6(1), 3-17.

Plug, E., Webbink, D., \& Martin, N. (2014). Sexual orientation, prejudice and segregation. Journal of Labor Economics, 32(1), 123-159.

Ramos, V., Carvalho, C. C., \& Leal, I. P. (2005). Atitudes e comportamentos sexuais de mulheres universitárias: A hipótese do duplo padrão sexual. Análise Psicológica, 23(2), 173-185.

Reid, J. A., Elliott, S., \& Webber, G. R. (2011). Casual hookups to formal dates. Gender \& Society, 25(5), 545-568.

Reiss, I. L. (1956). The double standard in premarital sexual intercourse: A neglected concept. Social Forces, 34(3), 224-230.

Robinson, I., \& Jedlicka, D. (1982). Changes in sexual attitudes and behavior of college students from 1965 to 1980: A research note. Journal of Marriage and Family, 44(1), 237-240.

Roland, Gérard (2015). "Economics and Culture" in Emerging Trends in the Social and Behavioral Sciences (R. Scott and S. Kosslyn Eds.). Hoboken: John Wiley \& Sons.

Rudman, L. A., Fetterolf, J. C., \& Sanchez, D. T. (2012). What motivates the sexual double standard? More support for males versus female control theory. Personality and Social Psychology Bulletin, 39(2), 250-263.

Sakaluk, J. K., \& Milhausen, R. R. (2012). Factors influencing university students' explicit and implicit sexual double standard. Journal of Sex Research, 49(5), 464-476.

Scales, P. (1977). Males and morals: Teenage contraceptive behavior amid the double standard. The Family Coordinator, 26(3), $211-222$.

Scott, J. (1998). Changing attitudes to sexual morality: A cross-national comparison. Sociology, 32(4), 815-845.

Shoveller, J. A., Johnson, J. L., Langille, D. B., \& Mitchell, T. (2004). Socio-cultural influences on young people's sexual development. Social Science \& Medicine, 59(3), 473-487.

Siegel, K., \& Meunier, É. (2019). Traditional sex and gender stereotypes in the relationships of non-disclosing behaviorally bisexual men. Archives of Sexual Behavior, 48(1), 333-345.

Smith, G., Mysak, K., \& Michael, S. (2008). Sexual double standard and sexually transmitted illnesses: Social rejection and stigmatization of women. Sex Roles, 58(5-6), 391-401.

Sprecher, S., \& Regan, P. C. (1996). College virgins: How men and women perceive their sexual status. The Journal of Sex Research, 33(1), 3-15.

Sprecher, S., Treger, S., \& Sakaluk, J. K. (2013). Premarital Sexual Standards and Sociosexuality: Gender, Ethnicity, and Cohort Differences. Archives of Sexual Behavior, 42(8), 1395-1405.

Tomé, G., Gaspar de Matos, G. M., Simões, C., Camacho, I., \& Alves Diniz, J. (2012). How can peer group influence the behavior of adolescents: Explanatory model. Global Journal of Health Science, 4(2), 26-35.

Wilson, S. M., \& Medora, N. P. (1990). Gender comparisons of college students' attitudes toward sexual behavior. Adolescence, 25(99), 615-627.

Yost, M. R., \& Zurbriggen, E. L. (2006). Gender differences in the enactment of sociosexuality: An examination of implicit social motives, sexual fantasies, coercive sexual attitudes, and aggressive sexual behavior. Journal of Sex Research, 43(2), 163-173.

Young, M., Cardenas, S., Donnelly, J., \& Kittleson, M. J. (2016). Perceptions of peer sexual behavior: Do adolescents believe in a sexual double standard? Journal of School Health, 86(12), 855-863.

Zaikman, Y., \& Marks, M. J. (2014). Ambivalent sexism and the sexual double standard. Sex Roles, 71(9-10), 333-344.

Zaikman, Y., Marks, M. J., Young, T. M., \& Zeiber, J. A. (2016). Gender role violations and the sexual double standard. Journal of Homosexuality, 63(12), 1608-1629.

\section{Publisher's Note}

Springer Nature remains neutral with regard to jurisdictional claims in published maps and institutional affiliations. 